\title{
The dynamics of İzmir Bay under the effects of wind and thermohaline forces
}

\author{
Erdem Sayın and Canan Eronat \\ Institute of Marine Sciences and Technology, Dokuz Eylül University, İzmir, Turkey \\ Correspondence: Erdem Sayın (erdem.sayin@deu.edu.tr) \\ Received: 12 September 2017 - Discussion started: 16 October 2017 \\ Revised: 9 March 2018 - Accepted: 16 March 2018 - Published: 13 April 2018
}

\begin{abstract}
The dominant circulation pattern of İzmir Bay on the Aegean Sea coast of Turkey is studied taking into consideration the influence of wind and thermohaline forces. Izmir Bay is discussed by subdividing the bay into outer, middle and inner areas. Wind is the most important driving force in the İzmir coastal area. There are also thermohaline forces due to the existence of water types of different physical properties in the bay. In contrast to the two-layer stratification during summer, a homogeneous water column exists in winter. The free surface version of the Princeton model (Killworth's 3-D general circulation model) is applied, with the input data obtained through the measurements made by the research vessel $K$. Piri Reis. As a result of the simulations with artificial wind, the strong consistent wind generates circulation patterns independent of the seasonal stratification in the bay. Wind-driven circulation causes cyclonic or anticyclonic movements in the middle bay where the distinct İzmir Bay Water (IBW) forms. Cyclonic movement takes place under the influence of southerly and westerly winds. On the other hand, northerly and easterly winds cause an anticyclonic movement in the middle bay. The outer and inner bay also have the wind-driven recirculation patterns expected.
\end{abstract}

\section{Introduction}

İzmir Bay, located on the Aegean Sea coast of Turkey, was formed as a part of the Aegean Sea during the Pleistocene period. Later, it was partially filled with the silt carried by Gediz River (Maddy et al., 2012). The bay can be divided into three areas according to their physical characteristics (containing different water types and bathymetry, etc.): outer, middle and inner bays, as indicated in Fig. 1. The average depth in the outer bay is about $70 \mathrm{~m}$. It decreases significantly towards the inner bay to an approximate depth of $10 \mathrm{~m}$.

In the bay, three distinct water types exist: Aegean Sea Water (ASW), İzmir Bay Water (IBW) and İzmir Bay Inner Water (IBIW). The outer bay water type ASW has a greater volume than the other water types in the bay. Relatively small temporal changes are observed in its temperature and salinity values due to its large volume. The inner bay water type IBIW is the coldest in winter and its temperature varies from 9.1 to $13.9^{\circ} \mathrm{C}$. It has a maximum temperature in summer and changes from 24.6 to $27.5^{\circ} \mathrm{C}$. IBW is formed in the middle gyre area, influenced by the Gediz River inflow and by the upwelling and downwelling processes that are mainly driven by southerly and northerly winds, respectively. IBW seems to be a mixture of IBIW and ASW in winter. But it is a very distinct water type in summer with its higher salinity values varying between 39.6 and 39.9 psu (Sayin et al., 2006).

The water masses of shallow bays such as İzmir Bay have impacts on the Aegean Sea through temperature or saltcontrolled dense water cascading. For example, the dense IBW, which is always saltier than ASW in summer and denser in winter, flows near the coast of Foça over the topography into the Aegean Sea (Sayin et al., 2006; Eronat and Sayin, 2014).

The water exchange through some vertical sections can give a good estimate of the renewal time for the selected regions in Izmir Bay. The renewal time, which is important from a biological and chemical point of view, is found to be 46 and 29 days for the winter and summer case, respectively by considering the water exchange through the vertical section between İzmir Bay and the Aegean Sea (Sayın, 2003). The water input through Gediz River is relatively low (averaging about $40.3 \mathrm{~m}^{3} \mathrm{~s}^{-1}$ ) over 30 years compared 


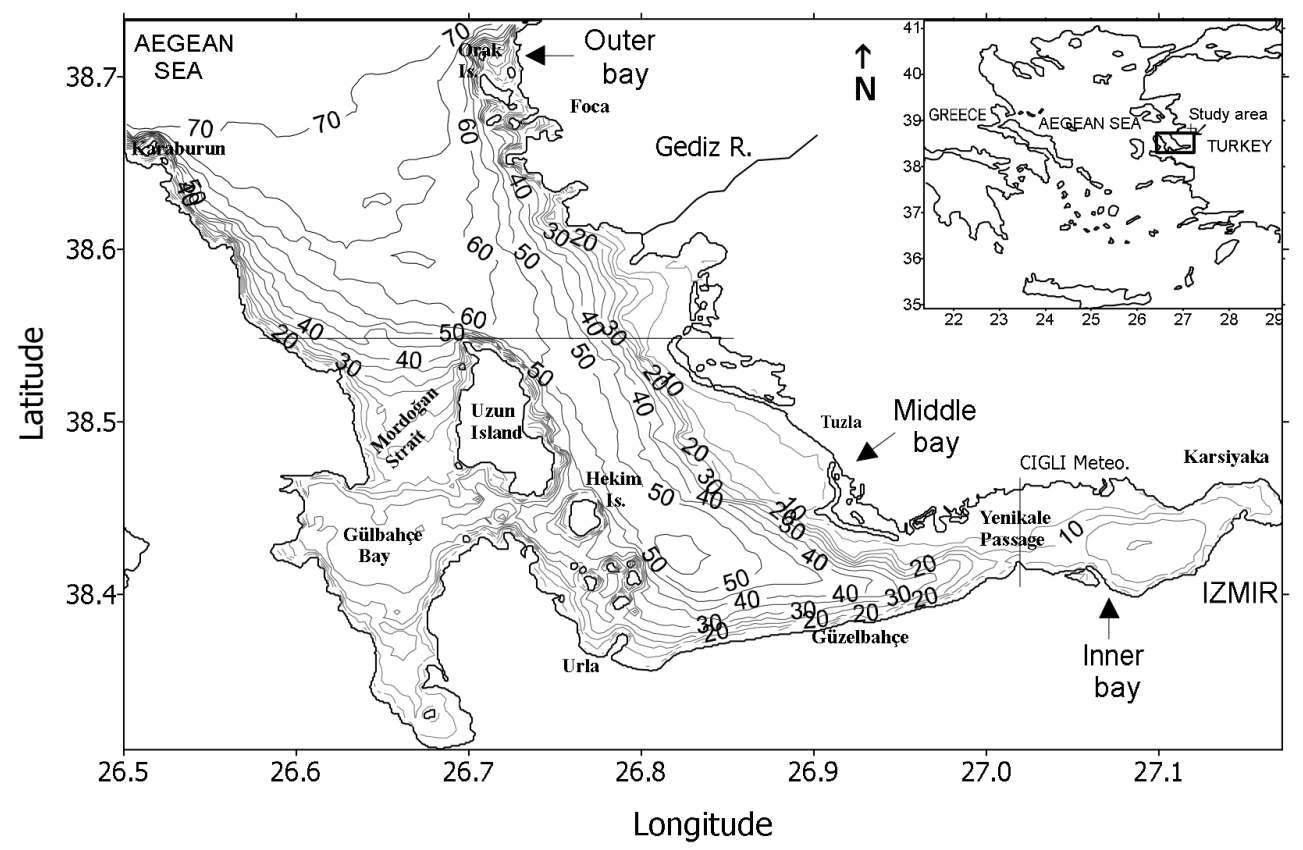

Figure 1. Location of İzmir Bay and study area bathymetry.

to the water exchange with the Aegean Sea (approximately $7000 \mathrm{~m}^{3} \mathrm{~s}^{-1}$ ). Since Gediz River used to discharge into the inner and middle bays until 1890, there is an important accumulation of sedimentation in the inner and middle bays. This situation, causing major differences in the bathymetric structure of the inner bay, has a very important role in the circulation there and avoids large-scale water exchange between the inner bay and the middle bay. The effect of shallowing caused by the previous Gediz River bed on the water motion in the inner bay section of İzmir Bay has been investigated by Karahan (2002) and the results have been discussed for various meteorological conditions. He determined that the shallowing in the middle bay entrance has an effect on the water input and output of the outer bay with the aid of a three-dimensional finite difference hydrodynamics model.

Suspended material and food can be trapped in the interfacial area between the water masses from the Aegean Sea and the interior parts of the bay. Therefore, these places are attractive locations for fish. Depending on the wind conditions and stratification in the water column, the current from the Karaburun area carries fish eggs and larvae originating in the Mediterranean into the small Gülbahçe Bay through the Mordoğan Passage and even further to the middle bay. This feature adds to the diversity of marine life, as can be observed from the various larvae found in Gülbahçe Bay (Sayın and Öztürk, 2006).

The analysis of the current system in the bay is quite recent: the first mathematical model study related to the circulation pattern of İzmir Bay is the depth-averaged twodimensional mathematical model given in Karahan (1988). The current system in the bay has been examined by
Saner (1994). He calculated the circulation pattern and water exchange between the different regions of İzmir Bay using two- and three-dimensional wind-driven mathematical models. Saner (2005) also compared his two models: the two-dimensional model solving the equations using the standard 2D-ADI method with the 3-D dimensional sigma coordinate model. Pazı (2000) studied the current system of the bay mainly in relation to the observations and has found that the current is driven by wind and also by thermohaline forces. Sayın (2003) investigated the important physical features based on observations and modeling studies. Sayın et al. (2006) ran the model with realistic forcing. In this study, our motivation is to understand the behavior of the current field when there is a strong wind, blowing from four main directions. If the wind continues for a long time, approximately more than $12 \mathrm{~h}$, the current fields in the bay are influenced by the wind and form wind-driven circulations. The biologist, chemist and other researchers can obtained a detailed pattern of the current field if they know from which direction the wind is blowing.

Beşiktepe et al. (2011) calculated the circulation pattern of İzmir Bay with a primitive equation model of the Harvard Ocean Prediction System. They identified the elements of the sub-basin-scale circulation and found that the size, structure and evolution of the main model circulation and gyres are in agreement with observations. In their simulations the main circulation of the bay is a cyclonic gyre which occupies almost the whole basin. This circulation is driven and modified by the wind and offshore forcing. Eronat (2011) and Eronat and Sayın (2014) studied the temporal evolution of the water characteristics of İzmir Bay, including the EMT (Eastern 

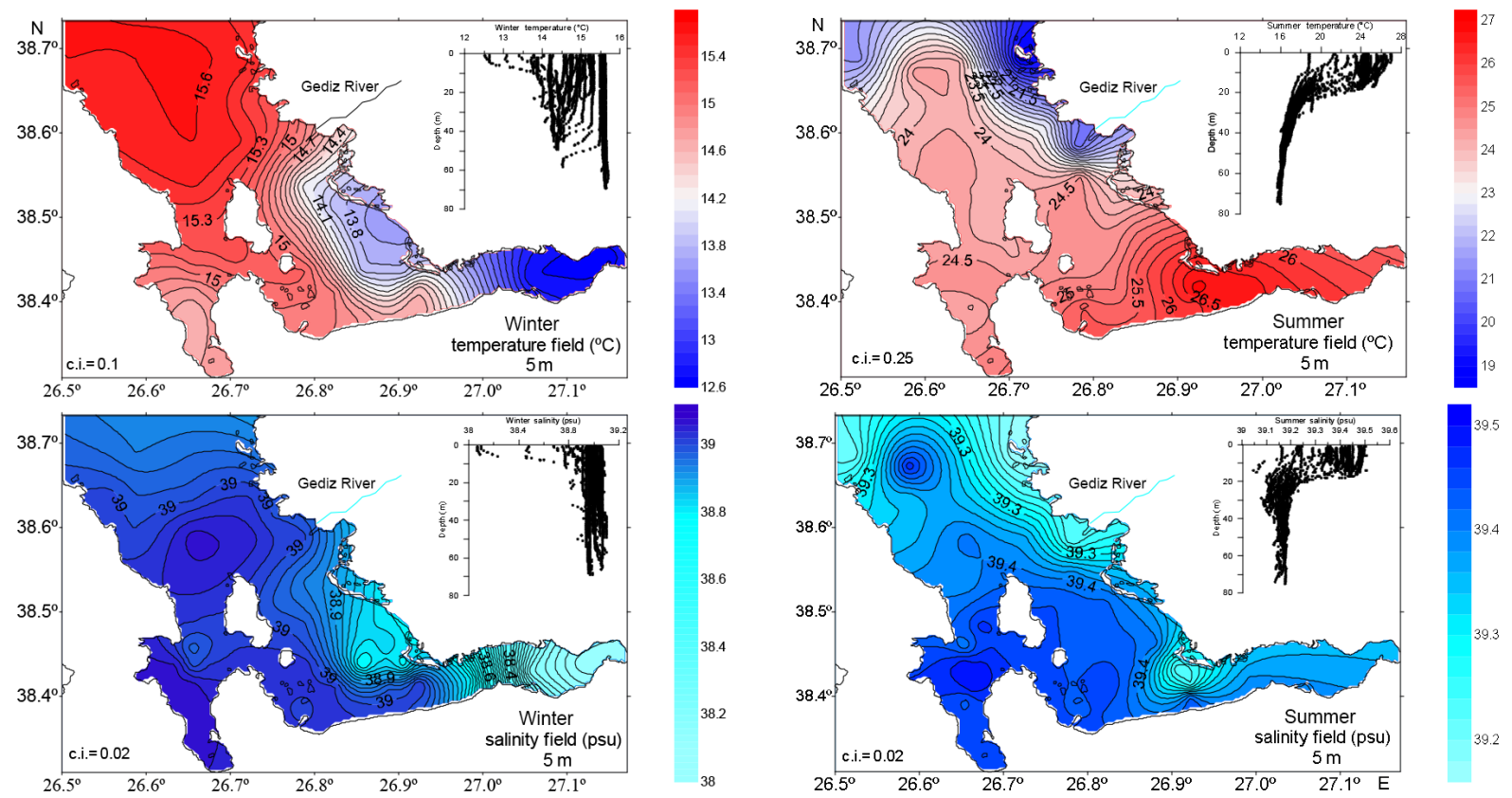

Figure 2. The winter and summer temperature and salinity fields given by the model as temperature and salinity distributions of the first level. The related profiles are at the upper-right corner of the figures.

Mediterranean Transient) period, giving information about the major deep-water formation episode and what followed in the Aegean Sea.

In the present study, emphasis is given to the dynamics of recirculation obtaining in İzmir Bay. These circulation patterns are formed under special wind conditions depending on background stratification. The seasonal regime of the current system and the formation of persistent or quasi-permanent water movements in the bay are relevant to studies on the biological or chemical oceanography of the bay.

This study can also be an example for the other bays along the coastal area of the eastern Aegean Sea. The bays play crucial roles in the formation of water masses in the Aegean Sea according to their water exchange potentials. A more solid foundation of our knowledge of the circulation and hydrography of İzmir Bay is therefore of considerably wider interest than merely regional.

Materials and methods of this study are explained briefly in the second section. The third section examines the recirculation patterns that are frequently observed in the İzmir Bay environment. The last section is the conclusion.

\section{Material and methods}

Physical oceanographic measurements were initiated in 1988 in İzmir Bay. Regular measurements have been conducted since 1996 with a Seabird CTD (conductivity, temperature and depth) system.
A $z$-level Killworth's 3-D general circulation model based on the primitive equations described by Bryan (1969) and Cox (1984) is applied to İzmir Bay. The specific model configuration used here is an explicit free surface version of the Princeton model, developed by Killworth et al. (1989). The Killworth model filters the fast oscillations, letting geostrophic balance remain after the establishment of the steady current. The steady current is achieved by controlling the kinetic energy of the system. The integration is stopped as soon as the kinetic energy level reaches a plateau. To set a realistic stratification, selected winter and summer hydrological cruise CTD data are prescribed in the model as an initial condition. The winter and summer initial temperature and salinity values are shown in Fig. 2. The simulations were used to define the general circulation patterns of the bay by using real topography.

The model has been using for a long time at the Institute of Marine Science and Technology. The validation with observations was carried out and first results were obtained by Sayın (2003) and Sayın et al. (2006). Comparison with the other models at the institute (a primitive equation model of the Harvard Ocean Model and FVCOM (the Unstructured Grid Finite Volume Community Ocean Model)) was done and achieved good agreement. The model was previously applied to the Baltic Sea and the straits between the Baltic and North seas (Sayın and Krauss, 1996), justifying that this model can be used also for small seas as well as straits and channels. Sayın et al. (2006) has run the model with realistic forcing for İzmir Bay. 


\begin{tabular}{|c|c|c|c|c|c|c|c|c|c|c|c|c|c|}
\hline \multirow[t]{2}{*}{ Month of year } & Jan & Feb & Mar & Apr & May & Jun & Jul & Aug & Sep & Oct & Nov & Dec & Year \\
\hline & 01 & 02 & 03 & 04 & 05 & 06 & 07 & 08 & 09 & 10 & 11 & 12 & $1-12$ \\
\hline \multirow{2}{*}{$\begin{array}{l}\text { Dominant wind direction } \\
\text { Wind probability }==4 \text { Beaufort }(\%)\end{array}$} & 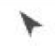 & $r$ & 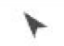 & $r$ & - & $y$ & 4 & + & 4 & $\mathbf{r}$ & $T$ & $\vdash$ & $\mathbf{Y}$ \\
\hline & 33 & 35 & 36 & 34 & 40 & 46 & 60 & 48 & 35 & 20 & 22 & 25 & 36 \\
\hline \multicolumn{14}{|l|}{ Average wind speed $\left(\mathrm{m} \mathrm{s}^{-1}\right)$} \\
\hline & 5 & 5 & 5 & 5 & 5 & 6 & 6 & 6 & 5 & 4 & 4 & 4 & 5 \\
\hline Average air temp. $\left({ }^{\circ} \mathrm{C}\right)$ & 11 & 12 & 15 & 19 & 24 & 30 & 32 & 32 & 27 & 22 & 17 & 11 & 21 \\
\hline
\end{tabular}

Figure 3. Monthly and yearly wind direction and average wind intensity from 2000 up to the present for the İzmir Bay environment. The arrows point in the direction that the wind is blowing. The last column indicates the dominant wind and its intensity (https://www.windfinder. com).

Table 1. The model parameters chosen for the wind-driven circulation experiments.

\begin{tabular}{ll}
\hline Parameters & \\
\hline Horizontal resolution & $500 \mathrm{~m}$ \\
Number of vertical layers & 6 \\
Layer thickness (m) (layers 1, 2, 3, 4, 5 and 6) & $5,10,15,15,15$ and $10 \mathrm{~m}$ \\
Horizontal eddy coeff. for momentum: & $1.0 \times 10^{5} \mathrm{~cm}^{2} \mathrm{~s}^{-1}$ \\
Vertical eddy coeff. for momentum & $1.0 \mathrm{~cm}^{2} \mathrm{~s}^{-1}$ \\
Horizontal eddy coeff. for heat & $1.0 \times 10^{5} \mathrm{~cm}^{2} \mathrm{~s}^{-1}$ \\
Vertical eddy coeff. for heat & $0.1 \mathrm{~cm}^{2} \mathrm{~s}^{-1}$ \\
Baroclinic time step & $200 \mathrm{~s}$ \\
Barotropic time step & $5 \mathrm{~s}$ \\
Bottom drag coefficient & $2.2 \times 10^{-3}$ \\
\hline
\end{tabular}

In this study, the model parameters chosen are given in Table 1. No tidal and heat forcing is included in the model. The density-driven experiment is conducted using the temperature and salinity fields (no wind) to understand the effect of stratification on the circulation pattern. Figure 3 shows monthly and annual wind direction and average wind intensity from 2000 up to the present for the İzmir Bay environment. The wind from the north is the predominant wind direction for İzmir Bay. The average wind speed is $5 \mathrm{~m} \mathrm{~s}^{-1}$.

In this study an attempt is made to understand the behavior of the current field under a strong wind. Therefore, the wind intensity is increased from 0 to $10 \mathrm{~m} \mathrm{~s}^{-1}$ in the model experiments testing which wind intensity is enough to simulate strong wind conditions. Then, the wind-driven experiment is conducted using wind from four main directions, including the direction of the predominant wind, with a constant intensity $\left(5 \mathrm{~m} \mathrm{~s}^{-1}\right)$ to simulate persistent wind conditions.

The model domain is connected to the Aegean Sea. Observed temperature and salinity values are prescribed at the boundary and relaxed during the rest of the model integration time. At the boundary, Stevens (1990) active open boundary condition for the tracer field, Orlanski (1976) radiation condition for the external mode was applied. Stevens active boundary was chosen to force the model with observed tem- perature and salinity values at the boundary. It was deemed suitable to choose radiation conditions for the barotropic part due to a lack of consistent surface elevation information related to the Aegean Sea general circulation dynamics.

The numerical experiments can be divided into two groups: one group focuses on the thermohaline circulation (defined as the circulation which evolves under the influence of the density-induced forces generated as a result of background temperature and salinity stratifications), and the other group is wind-driven circulation. The model integration is variable for every run. But it takes approximately 3 days. The background stratification remains unchanged from its original prescribed form because of the equilibrium is succeeded in a short time. This is the importance of wind-driven scenarios with a constant wind intensity. The model will not be in a steady state if we use an actual wind field to run the model.

It is certain that the open sea flow is very influential with regard to features in the real sea. In our case, we have no sea level measurements. It is not possible to get reliable sea level information from satellite data (TOPEX/POSEIDON) due to their coarseness. On the other hand, although İzmir Bay has a link with the Aegean Sea, the cape and islands off the northern part of the bay probably form a barrier for the development of a large sea level gradient which extends from the north to the opening of Izmir Bay into the Aegean Sea.

\section{Results and discussions}

The representation of recirculation patterns that are formed by winter and summer stratification in the water column is given as a result of thermohaline circulation in Fig. 4.

First we describe the water types related to the stratification in the bay. The existing water types (Sayin et al., 2006) in the inner, middle and outer bay evolving under the different physical processes and mechanisms influence the water circulation in the bay. Of the water types, İzmir Bay Water (IBW) is denser than the Aegean Sea Water (ASW) in winter, and the expected thermohaline circulation is cyclonic 


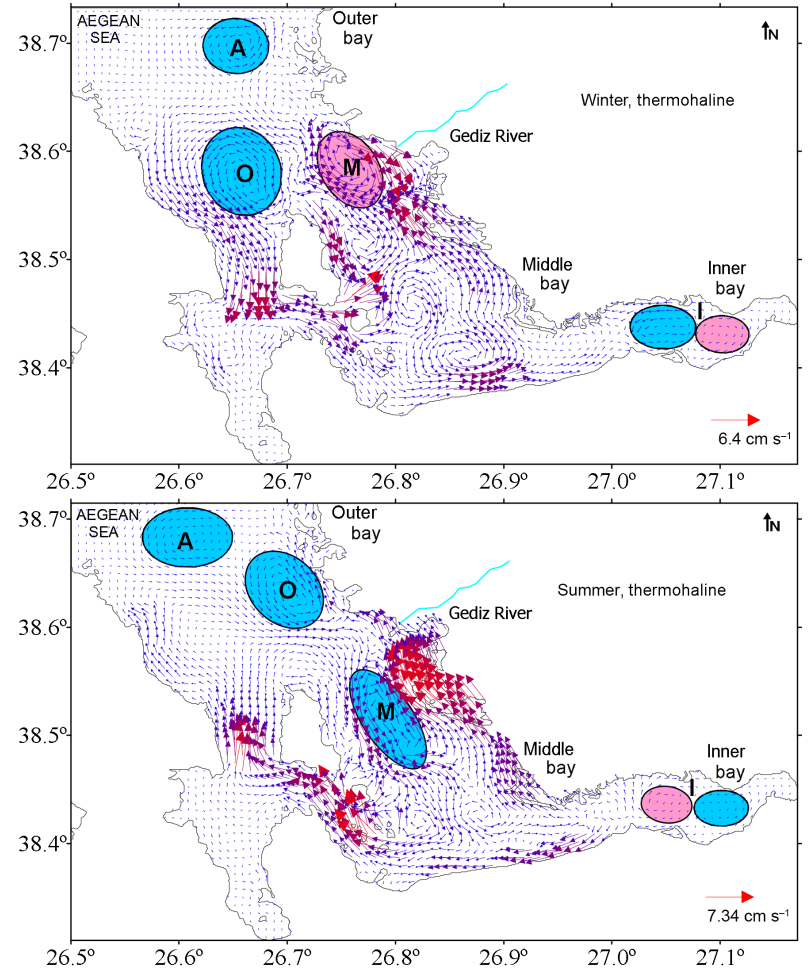

Figure 4. The winter and summer thermohaline circulation (depth averaged) in the bay.

along the basin width (Fig. 4 upper panel). This means that the dense IBW tends to flow along the east coast towards the Aegean Sea and the less dense ASW that enters near Karaburun flows through the Mordoğan Passage into the middle bay.

The outer bay water is always denser than the middle and inner bay waters because of having lower temperatures near the Aegean Sea in summer. Therefore, the flow from the Aegean Sea goes southwards; it follows a path in the middle of the outer bay, turns towards Gediz River and then flows near the east coast of Uzun Ada and bifurcates (Fig. 4). One branch combines with the current on the west coast, and the other branch combines with the strong current on the east coast forming a big cyclonic circulation in the middle area. The coastal currents at both sides flow northwards, compensating for the flow from the Aegean Sea. The current on the east coast leaves İzmir Bay near the coast of Foça. The summer circulation pattern is complicated compared to the pattern obtained for winter circulation. A vertically stratified water column changes the behavior of the current during summer.

By contrast, outer bay water is less dense than the middle and inner bay waters in winter because of having a higher temperature. Comparing winter patterns with the patterns formed in summer indicates that, unlike the cyclonic circulation patterns A (Aegean Recirculation Pattern) and $\mathbf{O}$ (Outer Bay Recirculation Pattern) in the outer bay, the pattern $\mathbf{M}$
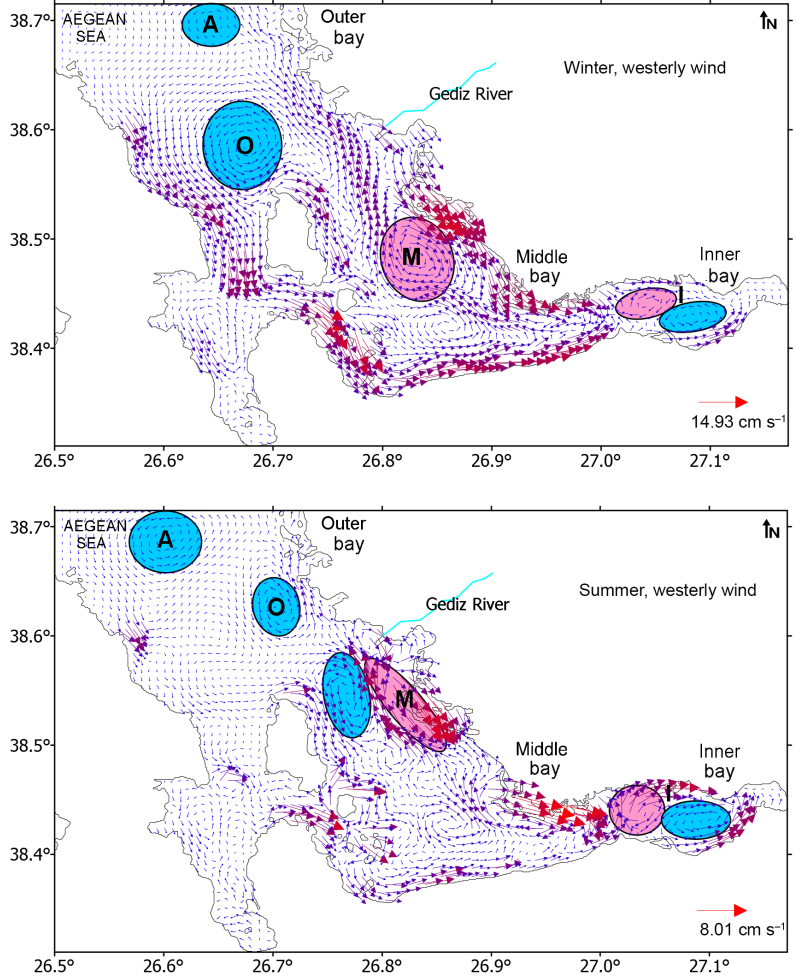

Figure 5. The barotropic current pattern (depth averaged) in the case of westerly wind in winter and in summer.

(Middle Bay Recirculation Pattern) changes sign. The thermohaline circulation I (Inner Bay Recirculation Pattern) is very weak in the inner bay in both seasons, with a dipole shape that changes sign from winter to summer (Fig. 4).

After analysis of thermohaline circulations, some model experiments are conducted using the winds from four main directions: westerly, easterly, northerly and southerly. Persistent westerly wind changes thermohaline cyclonic circulation, and homogeneous winter water is immediately under the influence of wind (Fig. 5). Coastal jets are produced along both coasts in the wind direction and a slow return flow compensates for this transport in the central area of the basin, as explained in the literature. In the case of a westerly wind, as expected, characteristic flows near both coasts are in the wind direction. The recirculation pattern $\mathbf{M}$ is anticyclonic due to stronger current near the east coast of the bay being established relative to the coastal current near the east coast of Uzun Ada. This pattern $\mathbf{M}$ is also anticyclonic in summer, but it is not well-developed. This means that stratification can play an important role in the current system.

In the inner bay, recirculation dipole pattern $\mathbf{I}$ is observed both in summer and in winter with the same sign. There is no significant communication between inner and middle bays because of the existence of a narrow passage (Yenikale passage). The numerical experiment was conducted to show the development of circulation in the inner bay by increasing the 

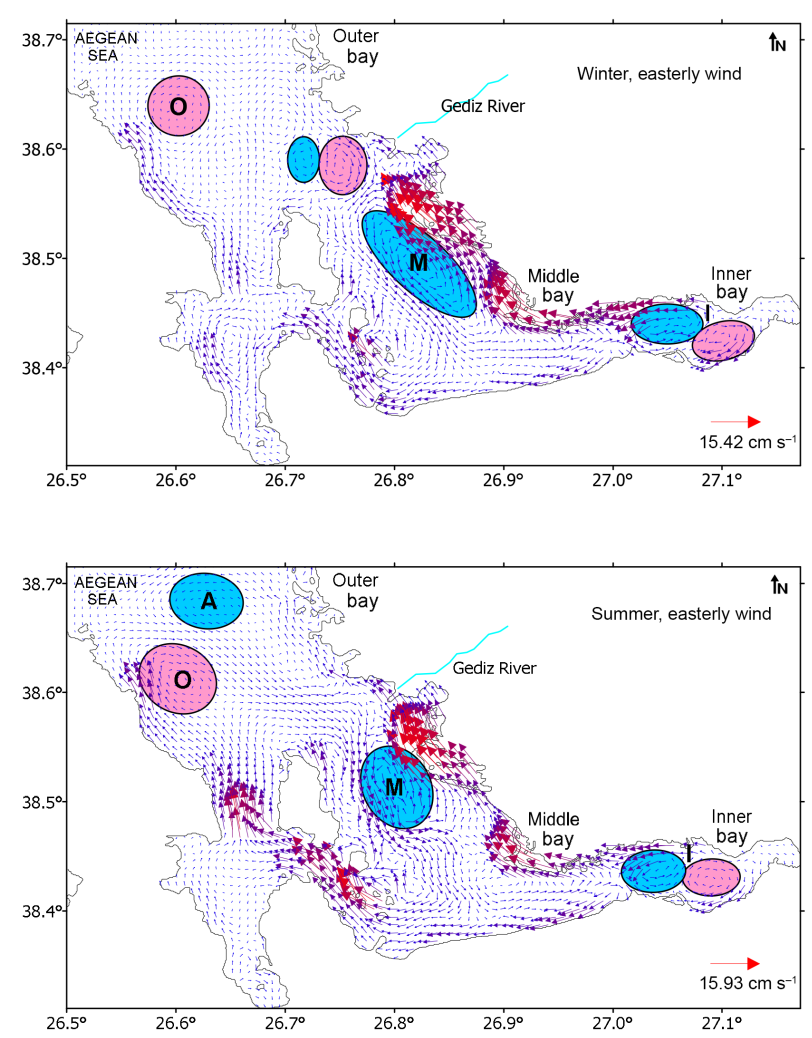

Figure 6. The barotropic current pattern (depth averaged) in the case of an easterly winder in winter and in summer.

wind intensity from 0 to $5 \mathrm{~m} \mathrm{~s}^{-1}$. The current, not only in the inner bay, but also in the other regions of the bay begins after a certain wind speed is exceeded. The current is very weak in the inner bay without the existence of wind force. The currents become stronger with increasing wind speed. Recirculation patterns which exist in the middle bay become welldeveloped after the increase of wind intensity above approximately $2.5 \mathrm{~m} \mathrm{~s}^{-1}$ and are observable both in the barotropic field and in certain layers.

In a similar manner, the current pattern of the bay can be analyzed for the other wind conditions in the same was as already done for the westerly wind. The current system is explained, giving emphasis only to the recirculation patterns forming in the bay. For example, the closed circulation pattern $\mathbf{M}$ has an anticyclonic character in westerly and northerly wind conditions (Figs. 5 and 7), and has a cyclonic character in other wind conditions, i.e., easterly and southerly (Figs. 6 and 8) for both seasons. Because of existing strong stratification in summer, a dipole forms in the middle area instead of one anticyclonic circulation (Figs. 5 and 7).

Circulation pattern $\mathbf{I}$ generally has a dipole character in westerly and easterly wind conditions (Figs. 5 and 6). These poles change places (signs) with each other depending on changing wind directions. It has an anticyclonic character

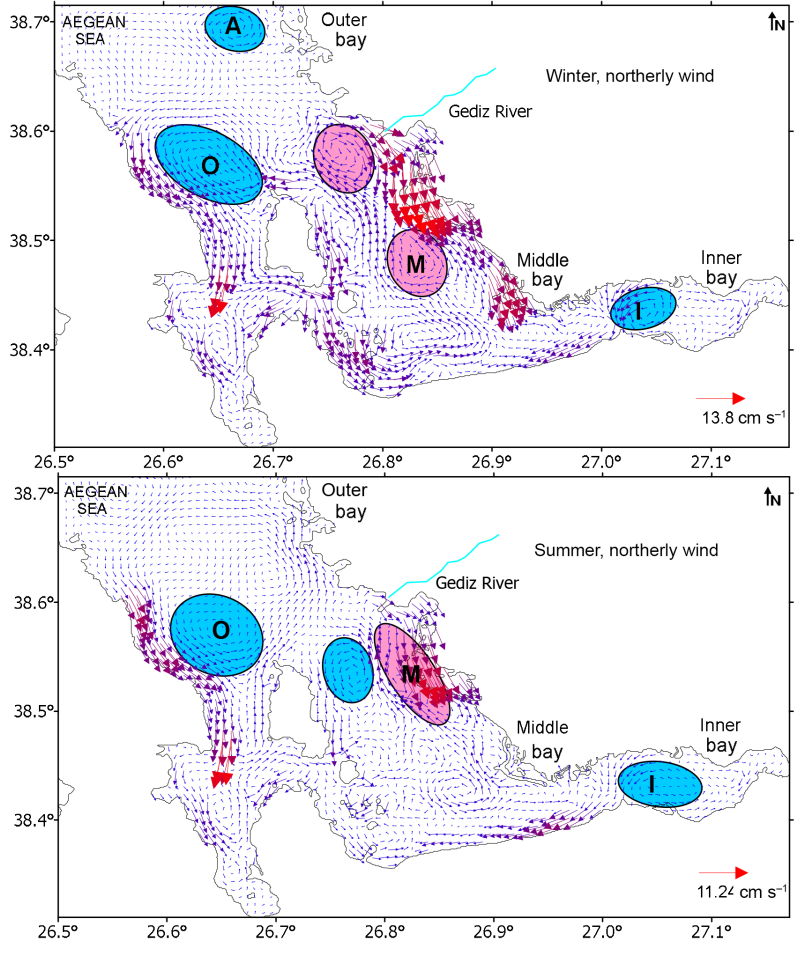

Figure 7. The barotropic current pattern (depth averaged) in the case of a northerly winder in winter and in summer.

in southerly wind conditions and a cyclonic character in northerly wind conditions for both seasons (Figs. 7 and 8).

Circulation pattern $\mathbf{O}$ forms mainly cyclonically in the case of westerly and northerly wind conditions (Figs. 5 and 7) and anticyclonically in the case of easterly and southerly winds in both seasons (Figs. 6 and 8).

Circulation pattern $\mathbf{A}$ is not persistent. If it forms, it will take a cyclonic form. This cyclonic behavior is seen both in summer and winter thermohaline circulations.

The small pattern formed above $\mathbf{M}$ has the same sign as $\mathbf{M}$ most of time. This circulation is formed first in the middle bay area, and later it moves towards the north. It sometimes combines with the patterns in the outer bay forming one big recirculation pattern. (If the sign of $\mathbf{M}$ and $\mathbf{O}$ is the same and $\mathbf{M}$ is very near the outer bay, these features combine with each other.)

The results obtained by the numerical method can be summarized schematically with respect to frequently seen recirculation patterns (Fig. 9). İzmir Bay is very sensitive to wind intensity and direction. A central recirculation pattern $\mathbf{M}$ is frequently present in the middle bay. Its direction of vorticity depends strongly on the recent wind conditions. The other recirculation patterns, $\mathbf{A}, \mathbf{O}$ and $\mathbf{I}$, are quasi-stationary. For example, the recirculation patterns seen in the outer bay near the Aegean Sea, $\mathbf{A}$ and $\mathbf{O}$, are developed mainly in the middle bay area. Sometimes they combine with the features in the middle area forming a larger cyclonic or anticyclonic 

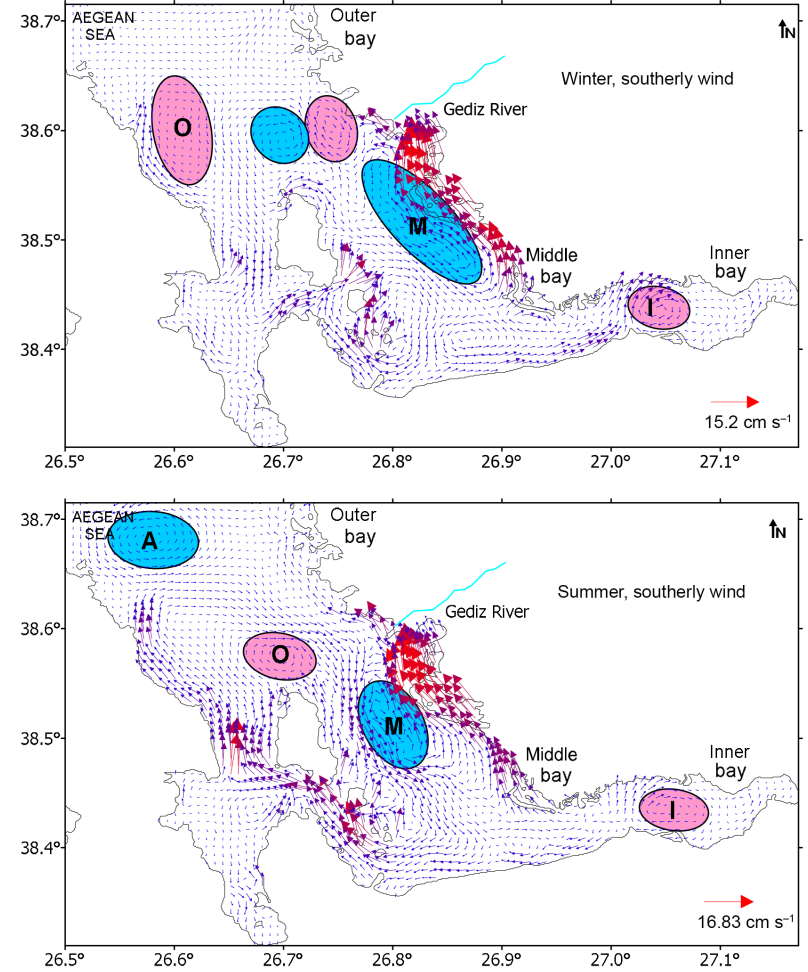

Figure 8. The barotropic current pattern (depth averaged) in the case of a southerly wind in winter and in summer.

pattern in the outer bay. They are mainly related to strong currents maintained near coastal shallow areas and gain velocity shear related to topography. The velocities are stronger in shallower areas compared to the velocities in relatively deeper parts. Recirculation Pattern $\mathbf{I}$ is observed in the inner bay, generally with a dipole shape.

\section{Conclusions}

The circulation and water movements of İzmir Bay can be summarized as outlined in the following.

The expected basin-wide circulation in İzmir Bay is cyclonic. The İzmir Bay Water flows along the east coast towards the Aegean Sea while the Aegean Sea Water enters the bay through the Mordoğan Passage in winter. However, in summer, although the circulation is cyclonic again, Aegean Sea Water flows into the middle bay near the east coast of Uzun Ada.

A (Aegean Recirculation Pattern) and $\mathbf{O}$ (Outer Bay Recirculation Pattern) form in the outer bay. The pattern most often observed, M (Middle Bay Recirculation Pattern), forms in the middle bay and I (Inner Bay Recirculation Pattern) is observed in the inner bay, generally with a dipole shape.

Pattern $\mathbf{M}$ has a cyclonic character in the case of southerly and easterly winds and has an anticyclonic character in the case of northerly and westerly winds. Sometimes in sum-

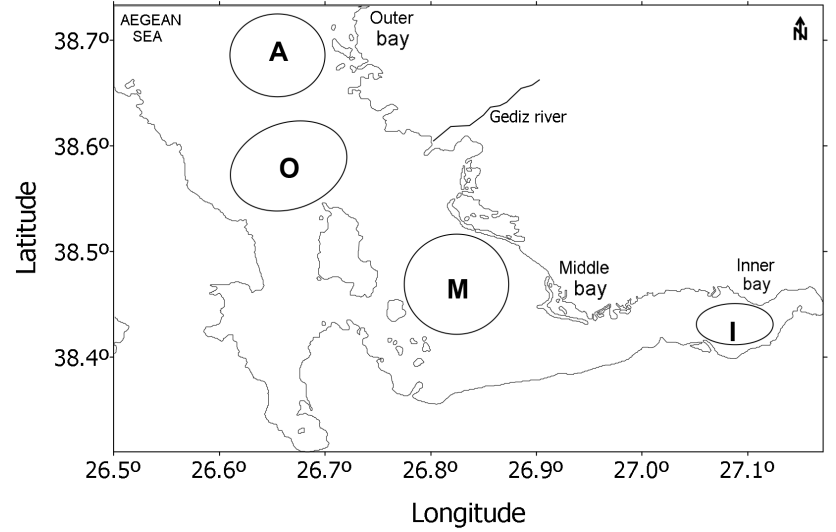

Figure 9. Frequently seen recirculation pattern in İzmir Bay.

mer, anticylonic circulations cannot be developed well because of the strong background thermohaline cyclonic circulation. The recirculation pattern formed above the $\mathbf{M}$ towards the Aegean Sea always has the same sign as M. This pattern forms first in the middle bay area, and it moves to the north. It sometimes combines with the other pattern in the middle bay, forming one big pattern. This shows us that the middle bay area plays an important role in the generation of closed recirculation patterns in the bay.

The cyclonic middle gyre $\mathbf{M}$ is important for the İzmir Bay environment for two reasons. The first is related to the dense water formation. The densest water (IBW) forms in the middle bay as a result of winter convection enhanced with cyclonic circulation in winter season. It causes dense water cascading from İzmir Bay to the Aegean Sea. The second reason is important from a biological point of view: upwelling brings nutrient-rich water to the surface.

The Outer Bay Recirculation Pattern $\mathbf{O}$ forms mainly anticyclonically in the case of southerly and easterly winds and cyclonically in the case of westerly and northerly wind conditions in both seasons.

The wind-driven recirculation pattern I almost has double poles in easterly and westerly wind conditions. These poles change places with each other depending on the wind direction. The dipole character of the circulation leads to cyclonic or anticyclonic behavior, respectively, in northerly and southerly wind conditions.

Circulation pattern $\mathbf{A}$ is not persistent. Its shape changes depending on the Aegean Sea boundary condition.

İzmir Bay research needs to bring all disciplines relating to it together. To do this, more modeling efforts besides the wind-driven circulations are necessary. The prognostic modeling approach can be a future challenge for the modeling of İzmir Bay by adding more meteorological information. 
Data availability. The data are not publicly accessible because the data set used was obtained in the framework of İzmir Bay Marine Research Project.

Competing interests. The authors declare that they have no conflict of interest.

Acknowledgements. The work was carried out in the framework of the Izmir Bay Marine Research Project. We acknowledge IMST/DEU for supporting the cruises. We also extend our thanks to the people who participated in the cruises. Special thanks are due to Deniz Ünsalan for his help with improving the manuscript.

Edited by: Markus Meier

Reviewed by: two anonymous referees

\section{References}

Beşiktepe, Ş. T., Sayın, E., İlhan, T., and Tokat, E.: İzmir Körfezi AkıntıDinamiğinin Model ve Gözlem Yardı mıla İncelenmesi, 7. KıyıMühendisliği Sempozyumu, Trabzon, 427-437, 2011.

Bryan, K.: A numerical method for the study of the circulation of the world ocean, J. Comput. Phys., 4, 347-376, 1969.

Cox, M. D.: A primitive equation, 3-dimensional model of the ocean, GFDL Ocean Group Technical Report No. 1, 1984.

Eronat, C.: Hydrography of the bays along the eastern coast of the Aegean sea. PhD, Graduate School of Natural and Applied Sciences, Dokuz Eylul University, İzmir, Turkey, 144 pp., 2011.

Eronat, C. and Sayın, E.: Temporal evolution of the water characteristics in the bays along the eastern coast of the Aegean Sea: Saros, İzmir, and Gökova bays, Turk. J. Earth Sci., 23, 53-66, 2014.

Karahan, H.: Mathematical modelling of coastal and bay currents with an application for İzmir Bay. PhD, Graduate School of Natural and Applied Sciences, Dokuz Eylul University, İzmir, Turkey, 174 pp., 1988 (in Turkish).

Karahan, H.: The Impacts of Sedimentation Caused in İzmir Bay by Gediz River on Circulation and Water Quality, in: Coastal Environment, Vol. 8, Sect. "Hydrodynamics and Transport Modelling”, edited by: Brebbia, C. A., 309-318, WIT Press, Southampton, Boston, 2002.
Killworth, P. D., Stainforth, D., Weeb, D. J., and Paterson, S. M.: A free surface Bryan-Cox-Semtner model, Institute of Oceanographic Sciences, Deacon Laboratory Internal Report, 270 pp., 1989.

Maddy, D., Veldkamp, A., Jongmans, A. G., Candy, I., Demir, T., Schoorl Van der Schrieka, J. M. T., Stemerdinkf, C., Scaifeg, R. G., and Van Gorp, W.: Volcanic disruption and drainage diversion of the palaeo-Hudut River, a tributary of the Early Pleistocene Gediz River, Western Turkey, Geomorphology, 165, 6277, 2012.

Orlanski, I.: A simple boundary condition for unbounded hyperbolic flows, J. Comput. Phys., 21, 251-269, 1976.

Pazı, I.: The Current System and Its Effect on the Pollution in İzmir Bay. Msc, Graduate School of Natural and Applied Sciences, Dokuz Eylul University, İzmir, Turkey, 2000.

Saner, E.: A 3-dimensional model for coastal and estuarine waters embedded in a PC-based IDE, PhD, Graduate School of Natural and Applied Sciences, Dokuz Eylul University, İzmir, Turkey, 1994.

Saner, E.: A 3-Dimensional Model for Coastal and Estuarine Waters, in: Bio-Geo-Chemical Processes in Coastal Seas and Estuaries, edited by: Uslu, O., Ozerler, M., and Sayın, E., Piri Reis Science Series, 1, 99-114, 2005.

Sayın, E.: Physical features of the İzmir Bay, Continental Shelf Research, 23, 957-970, 2003.

Sayın, E. and Krauss, W.: A Numerical Study of the Water Exchange Trough the Danish Straits, Tellus A, 48, 324-341, 1996.

Sayın, E. and Öztürk, C.: Importance of physical properties water for the site selection in the Izmir Bay, in: Proceeding Book of International Conference on "Coastal Oceanography and Sustainable Marine Aquaculture, edited by: Chouikhi, A., Saad, S., Hoque, M. A., and Shaleh, S. R. M., Confluence\&Synergy", 428-439, 2006.

Sayın, E., Pazı, I., and Eronat, C., Investigation of Water Masses in İzmir Bay, Western Turkey, Turk. J. Earth Sci., 15, 343-372, 2006.

Stevens, D. P.: On open boundary conditions for three dimensional primitive equation ocean circulation models, Geophys. Astro. Fluid, 51, 103-133, 1990. 